Saint Louis University School of Law

Scholarship Commons

All Faculty Scholarship

1998

\title{
Research Report: A Preliminary Analysis of Medical Futility Decisionmaking: Law and Professional Attitudes
}

Richard L. Wiener Ph.D.

Saint Louis University, Department of Psychology

David Eton M.A.

Saint Louis University, Graduate Student

Vincent P. Gibbons M.D.

Saint Louis University, Department of Neurology, Health Sciences Center, and Comprehensive Epilespy Care Center for Children and Adults

Jesse A. Goldner J.D.

Saint Louis University School of Law, Center for Health Law Studies

Sandra H. Johnson J.D.

Saint Louis University School of Law, Center for Health Law Studies

Follow this and additional works at: https://scholarship.law.slu.edu/faculty

Part of the Health Law and Policy Commons

\section{Recommended Citation}

Johnson, Sandra H. and Weiner, Richard and Gibbons, Vincent P. and Eton, David and Goldner, Jesse, Research Report: A Preliminary Analysis of Medical Futility Decisionmaking: Law and Professional Attitudes (1998). Behavioral Science and the Law, Vol. 16, p. 497, 1998.

This Article is brought to you for free and open access by Scholarship Commons. It has been accepted for inclusion in All Faculty Scholarship by an authorized administrator of Scholarship Commons. For more information, please contact erika.cohn@slu.edu, ingah.daviscrawford@slu.edu. 


\title{
Research Report A Preliminary Analysis of Medical Futility Decisionmaking: Law and Professional Attitudes
}

\author{
Richard L. Wiener*, Ph.D., David Eton, M.A., \\ Vincent P. Gibbons, M.D., Jesse A. Goldner, \\ J.D., and Sandra H. Johnson, J.D.
}

Judicial decisions reviewed in this article indicate that courts have taken two disparate approaches to disputes over futility of treatment. To explore whether a consensus on medical futility is developing among hospitals, the authors conducted a nationwide survey of health care professionals at hospitals. Respondents assigned importance ratings to factors used in recent futility decisions made at their institutions. The resulting importance ratings showed significant variation by characteristics of the institution (comparing respondents from for-profit, not-for-profit, and government hospitals) and by profession of the respondent (comparing physicians and nurses). The respondents' judgments endorsed three distinct strategies for making futility decisions (i.e., emphasis on the patient's decision preferences, providing for the patient and family, and adhering to objective medical and social norms). (C) 1998 John Wiley \& Sons, Ltd.

Conflict between a patient (or surrogate) insisting on treatment and a doctor refusing to furnish it has defined the debate over medical futility to date (Asch, Hansen-Flasche, and Lanken, 1995; Daar, 1993; Lee, Swinburne, Fedullo, and Wahl, 1994). Whether the treatment choice appropriately rests exclusively in the hands of the physician in instances where therapy is claimed to be futile, rather than within the authority of the patient or surrogate, is the focus of the conflict (Brennan, 1992; Morreim, 1994; Veath and Spicer, 1992).

* Correspondence to: R. L. Wiener, Department of Psychology, St. Louis University, 221 North Grand Blvd, St. Louis, MO 63193, Email: WIENERRL@SLU.EDU

Dr. Wiener is a Professor of Psychology at St. Louis University, David Eton is a graduate student at St. Louis University, Dr. Gibbons is with the Department of Neurology, Health Sciences Center, St. Louis University, and Comprehensive Epilepsy Care Center for Children and Adults, P.C., St. Louis, Missouri. Professor Goldner and Professor Johnson are with the Center for Health Law Studies, St. Louis University School of Law; Center for Health Law Studies.

Contract grant sponsor: Beaumont Faculty Development Fund of Saint Louis University. 
Treatment that does not benefit the patient is generally viewed as futile, but significant disagreement exists over the definition of "benefit". Some argue that "futility" applies only to those instances where the treatment will not accomplish the physiological effect which is being sought. Others claim that interventions which will extend life but without consciousness are also medically futile (Cranford and Gostin, 1992; Miles, 1992; Schneiderman, Faber-Langendoen, and Jecker, 1994; Solomon, 1993; Truog, Brett, and Frader, 1992). Part of the definitional battle is the issue of the appropriate scope of physician discretion regarding such decisions.

\section{Case Law}

Decisions from the courts are similarly in conflict regarding the proper limits of physician control. The leading judicial cases on medical futility have held that treatment must be maintained as directed by the patient or surrogate even in the face of the doctor's or hospital's objection. These decisions rested on varying legal grounds and no uniform rationale has appeared. For example, the Court of Appeals decision in In re Baby K (1994) is based on the federal Emergency Medical Treatment and Labor Act, while the District Court in the same case relied on several statutes including the federal Americans with Disabilities Act (as cited in In re Baby K, 1994). The Georgia Supreme Court in In re fane Doe (1992) interpreted a state consent statute to require the consent of both parents if treatment was to be withheld; and the probate court in In re Wanglie (1991) relied on guardianship principles to find that the patient's husband was in the best position to act on behalf of his wife.

This invariable denial of physician discretion, however, has not extended to malpractice actions where there has been a tradition of deference, as a matter of law, to the standards of professional practice. Both judges and juries generally have been disinclined to punish physicians for their decisions in situations which were not presented to the courts for resolution prior to discontinuation of treatment. Thus, a trial court jury in Gilgunn v. Massachusetts (Mass. Sup. Ct. 1995) (as cited in New York Times "Withholding case", 1995) refused to hold the hospital or physician liable when they issued a do-not resuscitate (DNR) order in the face of an objection voiced by the patient's daughter. Similarly, in Morgan v. Olds (1987) an Iowa appellate court refused to award damages on a number of legal bases in a malpractice action where the doctor wrote a DNR order over the spouse's objection. In Hartsell v. Fort Sanders Regional Medical Center (1995) and in LaSalle National Trust v. Swedish Covenant Hospital (1995) the courts denied plaintiffs' claims where a physician removed life support from an infant assessed as too premature to survive. These malpractice cases, in contrast to the "medical futility cases", indicate that a physician may be permitted to withhold treatment despite the patient's or surrogate's wishes to the contrary, and still avoid civil liability in certain circumstances.

A more complete review of the state of the law which addresses the wide range of situations in which claims of medical futility are made, including state ${ }^{1}$ and

\footnotetext{
${ }^{1}$ See, for example, the Health Care Decisions Act, Md. Code Ann., Health-Gen. (1984) and the Health Care Decisions Act, Va. Code Ann (1994). 
federal statutes, ${ }^{2}$ and common law duties of informed consent, ${ }^{3}$ produces an even more complex impression. Goldner, Johnson, and Wiener (1997) present a more detailed analysis of the law and of hospital policies with regard to these issues. Nonetheless, the two lines of cases presented here seem to demonstrate widely differing views as to the legal status of medical futility. The lack of a strong professional or social consensus on the issue may underlie the ambiguity in legal standards. The purpose of this research was to identify the beliefs and attitudes that professionals say they use when they make futility decisions. Our goal was to describe any emerging consensus or the differences among professional or institutional perspectives that stand in the way of reaching such a consensus. We believe that any meaningful resolution to the policy confusion concerning futility judgments ought to begin by examining the decision principles that health care providers and administrators endorse. Our survey presented a list of potential criteria along with rating scales that asked the respondents (i.e., physicians, nurses, and administrators) to indicate the importance of each of the factors in recent decisions that were made at their hospitals. While our conclusions are essentially based on statistical comparisons, we collected the "to be rated" factors after carefully reviewing ethical commentaries, case law, and published empirical investigations of end of life decision making. In the final analysis our investigation employed a model building as opposed to a model testing methodology.

\section{METHOD}

\section{Respondents}

The authors sent the Life Sustaining Treatment Survey to 1990 hospitals across the United States. ${ }^{4}$ Each address carried an American Hospital Association (AHA) code which provided basic identifying information for the hospital. Two waves of surveys were mailed. The second wave was mailed to all hospitals which did not respond to the first mailing.

One thousand seven hundred and thirty-four $(87 \%)$ of the surveyed institutions were general medical facilities and $266(13 \%)$ were specialty institutions. The majority were acute care hospitals $(n=1795,90 \%)$.

Twenty-eight percent of the original surveyed population, $15 \%$ in the first wave and $13 \%$ in the second wave, returned completed surveys $(N=536)$. To measure the effects of non-responding on the representativeness of our data, we conducted a contingency table analysis (see Table 1) in which type of hospital was one factor and response status was a second factor. The data for non-respondents were gathered from the AHA codes and the corresponding schedule of AHA demographic information. We compared the breakdown of hospital type among non-respondents, wave one respondents and wave two respondents. Wave one respondents were those

\footnotetext{
${ }^{2}$ See, for example, the Americans with Disabilities Act, the Child Abuse Prevention and Treatment Act, and the Rehabilitation Act of 1973.

${ }^{3}$ See, for example, Fohnson v. Thompson (1992) and LaSalle National Trust $v$. Swedish Covenant Hospital (1995).

${ }^{4}$ The authors purchased addresses of 2000 members of the American Hospital Association. These members were hospitals with more than 200 beds.
} 
Table 1. Number and Percent of Hospitals not Responding, Responding in Wave 1, and Responding in Wave 2 as a Function of the Hospital's Controlling Organization

\begin{tabular}{lccc}
\hline & \multicolumn{3}{c}{ Response status } \\
\cline { 2 - 4 } Organization & Non-responders & Wave 1 responders & Wave 2 responders \\
\hline Non-religious not-for-profit & & & \\
$\quad N$ & 689 & 50 & 127 \\
$\quad$ Percent & 49 & 49 & 51 \\
State/local government & 293 & 17 & 43 \\
$\quad N$ & 20 & & 17 \\
$\quad$ Percent & 234 & 61 & 50 \\
Religious not-for-profit & 16 & 20 & 20 \\
$\quad \quad$ & 135 & 17 & 4 \\
$\quad$ Percent & 9 & 6 & 20 \\
For-profit hospitals & & & 8 \\
$\quad N$ & 89 & 23 & $249(13)$ \\
Percent & 6 & 8 & \\
Federal government & $1440(73)$ & $297(15)$ & \\
$\quad N$ & & & \\
Percent & & & \\
Total number (percent) & & & \\
\hline
\end{tabular}

Note. Percentages are based on column totals.

who responded to the first mailing and wave two respondents were those who would not have responded had they only received one mailing. Comparing the nonresponders to those who required a follow-up contact and to those who responded without reminder gives an estimate of the effect of non-responding on how well the achieved sample represents the sampled population. Table 1 shows that the largest difference between non-responders and wave 1 responders in any of the controlling organizations was only $4 \%$ (religious not-for-profit hospitals). Further, across all hospital categories the differences in the number of wave 1 and wave 2 respondents are trivial (i.e., never more than $2 \%$ for any category). Thus a careful review of Table 1 shows that overall the data adequately represent the types of organization that were selected from the American Hospital Association list. ${ }^{5}$

The mailings directed the recipients, Chief Executive Officers, to forward the questionnaires to the chair of the hospital ethics committees or to the individual otherwise responsible for fulfilling ethics committee functions. Of the respondents who returned the Life Sustaining Treatment Surveys, 94\% reported that their facilities had ethics committees. Eighty-one percent (443 of respondents) were members of ethics committees. Respondents included hospital administrators $(n=210,39 \%)$, nurses $(n=166,30 \%)$, physicians $(n=147,27 \%)$, risk management staff $(n=81,15 \%)$, pastoral care staff $(n=58,11 \%)$, Ph.D.'s $(n=42,8 \%)$, and combinations of all the above. Overall, the sample of 546 is representative of the surveyed population. ${ }^{6}$

\footnotetext{
${ }^{5}$ A chi square analysis showed that the type of hospital was not independent of responding status, $\chi^{2}(8$, $N=1986)=19.72, p<.02$. In large part this is due to the high power that resulted from the very large sample size. Therefore, even very small differences between percentages may reach conventional levels of significance.

${ }^{6}$ The percentages do not add to 100 because the survey allowed the respondents to indicate more than one professional identification.
} 
When asked whether the institution had an explicit written policy on decisions about medical futility, $137(26 \%)$ replied that they did and $400(74 \%)$ replied that they did not. Of the 137 who replied that they had futility policies, $115(84 \%)$ forwarded copies of one or more policies to the research team. We reviewed all of the policies received, and the results of that review are reported in Goldner et al. (1997) and Johnson, Gibbons, Goldner, Wiener, and Eton (1997).

\section{Materials}

A number of other studies of decision-makers have examined doctors' and others' attitudes toward life-sustaining treatments, (Christakis and Asch, 1993, 1995; Fox and Stucking, 1993; Nightingale and Grant, 1988; Solomon, O'Donnell, and Jennings, 1993) and medical futility decisions (Swanson and McCrary, 1994). The attitudes of individual providers are quite relevant even though other factors may influence behavior in particular situations (SUPPORT, 1995). This study differs from earlier studies in that it examines the attitudes toward medical futility decisions reported by hospital decision-makers and analyzes them as a function of the type of hospital in which the respondent works and the respondent's professional status. It also attempts to identify any consensus that exists among diverse decision-makers.

The Life Sustaining Treatment Survey used two sections to measure any existing consensus and differences. Section I inquired about the type and number of policies at each responding institution and about the professional status of the person completing the survey. Section II listed 23 factors and asked respondents to "reflect back on previously decided cases that involved decisions of medical futility and rate the importance of each of the factors ... in making those decisions". An interdisciplinary project committee developed the 23 factors after reviewing the literature and case law on medical futility. Two committee members were experienced members of hospital ethics committees. We included factors that represented the issues identified as important in the ethical and legal commentaries, in the case law, and among members of hospital ethics committees. Table 2 lists the factors. Respondents rated the importance of each factor on a 1-7 (1, very unimportant, 7, very important) scale.

\section{RESULTS}

\section{Data reduction}

We performed an exploratory principle components factor analysis with varimax rotation on the importance ratings of the 421 respondents who completed the 23 survey items. Results of the analysis produced a solution with seven factors with eigenvalues exceeding 1.00 . The seven factors accounted for $59 \%$ of the measurement variance. (Table 2 displays the rotated factor structure, and the loadings for each of the items.) Items are assigned to one and only one factor, provided that the item's loading on only that factor exceeded a value of .45. We named each factor according to the pattern of the items that loaded most heavily on that factor. The 
Table 2. Exploratory Factor Analysis of the 23 Decision Items

\begin{tabular}{|c|c|c|c|c|}
\hline Item & $\begin{array}{l}\text { Patient } \\
\text { Interests }\end{array}$ & $\begin{array}{l}\text { Patient } \\
\text { Decision }\end{array}$ & $\begin{array}{l}\text { Customary } \\
\text { Care }\end{array}$ & \\
\hline 9. Balance of benefits and harms to patient & .66 & & & \\
\hline 18. Best interests of the patient & .65 & & & \\
\hline 12. Likelihood of desired physiological effect & .65 & & & \\
\hline $\begin{array}{l}\text { 10. The wishes of a reasonable person in similar } \\
\text { circumstances }\end{array}$ & .62 & & & \\
\hline 21. Pain with or without treatment & .54 & & & \\
\hline 4. Quality of patient's life after treatment & .48 & & & \\
\hline 7. Decision by competent patient & & .83 & & \\
\hline $\begin{array}{l}\text { 6. Incompetent patient's prior preferences about } \\
\text { medical treatment }\end{array}$ & & .75 & & \\
\hline 8. Decision by incompetent patient's surrogate & & .72 & & \\
\hline 15. Local community standards and customs & & & .79 & \\
\hline $\begin{array}{l}\text { 14. Practice styles or customs of physicians on the } \\
\text { medical staff }\end{array}$ & & & .78 & \\
\hline \multirow{2}{*}{ 13. Experimental nature of the treatment } & & & .57 & \\
\hline & $\begin{array}{l}\text { Provide } \\
\text { Resources }\end{array}$ & $\begin{array}{l}\text { Patient } \\
\text { Needs }\end{array}$ & $\begin{array}{l}\text { Extending } \\
\text { Life }\end{array}$ & $\begin{array}{l}\text { Consistent } \\
\text { Judgment }\end{array}$ \\
\hline 20. Lack reimbursement for care & .72 & & & \\
\hline 5. Age of patient & .63 & & & \\
\hline 22. Ability of family to provide care & .60 & & & \\
\hline 19. Patient or family reasons for treatment decision & & .56 & & \\
\hline 11. Psychological needs of patient's family & & .55 & & \\
\hline 17. Immediacy of death without treatment & & .46 & & \\
\hline $\begin{array}{l}\text { 2. Probability of extending life during } \\
\text { hospitalization }\end{array}$ & & & .81 & \\
\hline $\begin{array}{l}\text { 3. Probability of extending life after } \\
\text { hospitalization }\end{array}$ & & & .76 & \\
\hline 1. Second, independent medical opinion & & & & .79 \\
\hline 23. Mission of the institution & & & & .59 \\
\hline
\end{tabular}

Note. The item numbers indicate the order in which they were presented in the survey. Item 16, the patient's religious beliefs, is not included in the table because its highest loading, on factor 5, was .35, less than the cut off point of .45. The full names for the seven factors are the following: Patient Interests, interests of the patient; Patient Decision, patient's decision preferences; Customary Care, customary care (i.e., treatment that would commonly be offered for patients suffering from life ending illnesses); Provide Resources, ability to provide resources for the patient; Patient Needs, needs of the patient or family; Extending Life, probability of extending life; and Consistent Fudgment, consistency of the judgment.

resulting seven factors and the percent of measurement variance each explained were the following. Factor 1, interests of the patient (22\%); Factor 2, patient's decision preferences $(10 \%)$; Factor 3, customary care (i.e., treatment that would commonly be offered for patients suffering from life ending illnesses) (7\%); Factor 4 , ability to provide resources for the patient ( $6 \%)$; Factor 5 , needs of the patient or family ( $5 \%$ ); Factor 6, probability of extending life (5\%); and Factor 7, consistency of the judgment $(4 \%){ }^{7}$ These seven factors represent the decision criteria that the respondents reported relying upon when making decisions about medical futility. They are termed "decision factors" in the remaining analyses. The decision factors

\footnotetext{
${ }^{7}$ We named Factor 7 "consistency of the judgment" because when its constituent items, a second medical opinion and the mission of the hospital, are considered together they assure that the futility decision meets some criteria external to the discretion of the doctor who provided the original diagnosis and prognosis.
} 
constitute an initial judgment matrix that captures the futility decision policies suggested by a national sample of 421 health care professionals. While we recognize that additional research that makes use of different methodologies (i.e., manipulated scenario studies, in-depth interviews, and expanded field surveys) with independent samples of health care professionals are needed to test these initial findings, these seven decision factors represent the first attempt to model the decision principles of medical futility judgments. In the analyses that follow, we tested the utility of these decision factors in discriminating between different types of hospital and differently trained professionals. We reasoned that different types of hospital are likely to endorse different treatment philosophies and that different health care professionals are trained to emphasize alternative treatment values. Therefore, the minimal criterion of usefulness for our decision factors is the ability of these factors to differentiate among types of hospital and types of professional.

\section{Hospital Status and Decision Factors}

We performed separate between-groups analyses of variance with controlling organization as the between-groups variable and factor scores for the seven decision factors as dependent measures. Differences were found among hospital types for interest of the patient, $F(4,414)=2.89, p=.022$; ability to provide resources for the patient, $F(4,414)=5.89, p<.001$; and consistency of the judgment, $F(4,414)=5.89, p<.006$. (Table 3 displays the mean factor scores for the significant effects along with the results of post hoc comparisons between means broken down by hospital type.)

The results indicate that respondents from state or local government-supported hospitals rated the patients' interests as less important than did respondents from either religious or non-religious not-for-profit hospitals when making decisions about medical futility. Further, respondents from government hospitals (state, federal, or local) were less concerned with the ability of the family to provide resources for the patients than were the private for-profit and not-for-profit hospitals. However, respondents from the for-profit hospitals rated the ability to provide resources as more important than did respondents from any of the other types of hospital. Notably, the religious, not-for-profit hospitals rated the consistency of the judgment (i.e., need for a second opinion and the institution's mission) as

Table 3. Decision Factor Mean Scores and Sample Size as a Function of the Hospital's Controlling Organization

\begin{tabular}{lcccc}
\hline Organization & $N$ & $\begin{array}{c}\text { Patient } \\
\text { Interests }\end{array}$ & $\begin{array}{c}\text { Provide } \\
\text { Resources }\end{array}$ & $\begin{array}{c}\text { Consistent } \\
\text { Judgment }\end{array}$ \\
\hline Non-Religious not-for-profit & 206 & $.04_{\mathrm{b}}$ & $.06_{\mathrm{b}}$ & $-.06_{\mathrm{b}}$ \\
Religious not-for-profit & 93 & $.14_{\mathrm{b}}$ & $.07_{\mathrm{b}}$ & $.30_{\mathrm{a}}$ \\
State/local government & 61 & $-.38_{\mathrm{a}}$ & $-.22_{\mathrm{ac}}$ & .00 \\
Federal government & 38 & -.06 & $-.50_{\mathrm{bc}}$ & $-.36_{\mathrm{b}}$ \\
For-profit hospitals & 21 & .10 & $.66_{\mathrm{a}}$ & -.06 \\
\hline
\end{tabular}

Note. The entries in the columns are mean factor scores, therefore the higher the number the more important is the decision factor for the respondents' futility judgments. Means in any column with different subscripts are significantly different at the .05 level using the Newman-Keuls post hoc comparisons procedure. 
more important than did the non-religious, not-for-profit hospitals or the federal government hospitals. The generalizability of this finding should be treated cautiously and requires further study, however, due to the slight overrepresentation of not-for-profit institutions among respondents.

\section{Respondent Status and Decision Factors}

To determine whether different types of respondent rely more heavily on different types of factor when making medical futility judgments, we performed a $2 \times 2$ between-group multivariate analysis of variance using whether or not the respondent was a member of the institutional ethics committee as one factor, and whether or not the respondent was a hospital administrator as a second factor. Factor scores for the seven decision factors served as dependent measures. A multivariate model was used because the focus was on differences between types of respondent across all decision factors. We repeated this analysis five more times replacing the second factor with whether or not the respondent was a a) medical doctor, b) doctor of philosophy, (c) nurse, (d) pastoral care staff, or (e) risk management staff.

A significant multivariate effect, Mult. $F(7,411)=5.14, p<.001$, was found for nurse status. Univariate analyses showed that compared to other respondents, nurses rated as more important customary care $(M=.20$ and -.09$), F(1,417)=$ $6.25, p=.013$ and needs of the patient or family $(M=.37$ and -.17$), F(1,417)=$ $18.74, p<.001$. These means are mean factor scores, therefore the higher the number the more important is the decision factor for the respondents' futility judgments. Nurses rated as less important the consistency of the medical judgment $(M=-.14$ and $.06 F(1,417)=6.25, p=.011$.

Another multivariate effect was found for medical doctors, Mult. $F(7,411)=$ 3.95, $p<.001$, and one for risk management staff, ${ }^{8}$ Mult. $F(7,411)=2.50$, $p=.016$. With regard to medical doctors, follow-up univariate tests showed that, compared to other respondents, physicians rated as less important customary care $(M=-.34$ and .12), $F(1,417)=13.62, p<.001$, and the ability to provide resources for the patient $(M=-.23$ and .08$) F(1,417)=8.21, p=.004$.

In summary, the data suggest differences among respondents relating to their profession. Nurses considered customary care and needs of the patient or family as more important and consistency of the medical judgment as less important than other factors. Physicians rated customary care and the availability of resources as significantly less important than other factors.

\section{Profile Analysis}

To determine whether respondents agreed upon specific strategies, we performed a profile analysis on the decision-making factors. First, we performed cluster analysis using the decision factors as variables to separate the respondents into groups of similar decision-makers. Cluster analysis separates observations (in this case respondents) into groups that are maximally distant from each other on the

\footnotetext{
${ }^{8}$ The effects of risk management status are not directly relevant to this paper and are not analysed here. 
Table 4. Decision Factor Mean Scores as a Function of Respondent Cluster Membership

\begin{tabular}{lccc}
\hline & \multicolumn{3}{c}{ Groups (I, II, and II) } \\
\cline { 2 - 4 } Decision factor & $\begin{array}{c}\text { Patient } \\
\text { Autonomy }\end{array}$ & $\begin{array}{c}\text { Patient } \\
\text { Protection }\end{array}$ & $\begin{array}{c}\text { Normative } \\
\text { Decision }\end{array}$ \\
\hline Interests of the patient & $.03_{\mathrm{c}}$ & $.05_{\mathrm{c}}$ & $.29_{\mathrm{a}}$ \\
Patient's decision preferences & $.27_{\mathrm{a}}$ & $-.02_{\mathrm{c}}$ & $-.02_{\mathrm{c}}$ \\
Customary care & $-.18_{\mathrm{c}}$ & $-.25_{\mathrm{c}}$ & $.33_{\mathrm{a}}$ \\
Ability to provide resources for the patient & $.24_{\mathrm{a}}$ & $.27_{\mathrm{a}}$ & $-.50_{\mathrm{c}}$ \\
Needs of the patient or family & $-1.03_{\mathrm{c}}$ & $.60_{\mathrm{a}}$ & $.31_{\mathrm{b}}$ \\
Probability of extending life & $.11_{\mathrm{b}}$ & $-.68_{\mathrm{c}}$ & $.63_{\mathrm{a}}$ \\
Consistency of the judgment & $.01_{\mathrm{b}}$ & $-.27_{\mathrm{c}}$ & $.28_{\mathrm{a}}$ \\
\hline
\end{tabular}

Note. The entries in the columns are mean factor scores, therefore the higher the number the more important is the decision factor for the respondents' futility judgments. Means in any row with different subscripts are significantly different at the .05 level of analysis using the Newman-Keuls post hoc comparisons for all means. The sample sizes for the three groups are 122, 142, and 136, respectively. See the accompanying text for a full description of each of the strategy types represented by the three groups.

criterion variables. Our cluster analysis separated the respondents into groups that were maximally different with regard to the importance ratings that they assigned to the decision factors. We used the scores on the seven factors recorded for each respondent hospital as criteria for the cluster analysis. Next, we performed multivariate analysis of variance using the cluster membership of respondents as a between subject factor and the decision factors as dependent variables.

The goal of this analysis was to identify groups of respondents who agree that certain factors are important in making futility decisions and who disagree with members of other groups about the importance of those and other decision factors. If the groups are significantly different on the decision factor ratings, then they represent distinctive decision policies about which identifiable groups of professionals agree.

Using the SPSS cluster algorithm ( $k$ means method) with analysis of variance tables, we found that with a five cluster solution in which we eliminated two clusters because of small sample size $\left(n_{4}=16, n_{5}=5\right)$ we were able to construct three remaining groups $\left(n_{1}=122, n_{2}=142\right.$, and $\left.n_{6}=136\right)$ for which we calculated a significant multivariate effect with all decision factors as dependent variables, $F(14,782)=69.34, p<.001$, and significant univariate $F$ values for all decision factors separately (all $p$ values less than .015). ${ }^{9}$ Thus, the solution to the cluster analysis was derived purely on an empirical basis. (Table 4 displays the three groups of respondents and the mean decision factor scores for each group. Included in Table 4 are post hoc analyses that indicate which mean scores are significantly different with the Newman-Keuls test.) The three groups of respondents form three distinct decision strategy types.

Group I is most concerned with both the patient's own decision preferences and the ability of the family to provide resources for the patient. The strategy adopted by the Group I decision-makers might be based on a policy of protecting the patient's autonomy and freedom within the resources available to support the patient, but

\footnotetext{
${ }^{9} F(2,397)$ for all the decision factors were the following: interests of the patient, $4.50, p=.012$; patient's decision preferences, $7.20, p=.001$; customary care, $15.68, p<.001$; ability to provide resources for the patient, 30.32, $p, .001$; needs of the patient or family, 208.60, <.001; probability of extending life, 86.40, $p<.001$; and consistency of the judgment, $11.31, p<001$.
} 
rejects the importance of psychosocial need factors (hereafter, patient autonomy group). Group II respondents rated as most important the ability to provide resources for the patient and the needs of the patient and family. Respondents in Group II rated least important the probability of extending the patient's life and the consistency of the judgment. The policy represented by the ratings of the Group II decision-makers might be to protect the patient, his or her family, and the institution from financial and social hardships which could result from any prolonged and hopeless illness (hereafter, patient protection group). Finally, Group III respondents rated the interests of the patient, customary care, the probability of extending life, and the consistency of the judgment as the most important factors. The least important factors were the ability to provide resources and the patient's decision preferences. ${ }^{10}$ The policy represented by Group III's strategy is to make the decision based upon medical and social norms that are defined from an objective, as opposed to subjective, point of view independent of the patient's perspective or resource obstacles (hereafter, normative decision group). ${ }^{11}$

\section{DISCUSSION AND LIMITATIONS}

Emerging from our analyses was a judgment matrix comprised of seven decision factors that captured the judgment policies of the professional health care staff who completed our surveys. We found that these factors discriminated among hospital types as well as professional health care workers. As to hospital type, these preliminary results suggest that there may be important differences among respondents from for-profit, not-for-profit and government hospitals. For example, respondents from for-profit hospitals rated the ability to provide resources as more important than did respondents from any other facilities. Additional comparisons showed significant effects for professional status on the decision factors. For physicians, our data failed to indicate positive predictors for futility decisions, suggesting a lack of consensus among physician respondents. In contrast, the data suggested that nurses did identify some common factors (i.e., customary care and the needs of the patient and family) in medical futility decisions. The data also suggested that there is no emerging consensus on decision-making strategy among respondents, but rather support of least three different approaches (i.e., emphasis on the patient's own decision preferences, emphasis on providing for the patient and her or his family, and emphasis on objective medical and social norms). It is unlikely that the law will realize its full potential to regulate futility judgments until explicitly articulated professional standards emerge. Effective regulations presuppose principled decision criteria that professionals bring to the end of life decisions. There is a need for continued empirical research to document and test judgment principles as more refined policy positions emerge.

\footnotetext{
${ }^{10}$ The factors, "interests of the patients" and "patients' decision preferences" can be distinguished as they are used in this context in that the former refers to the patient's needs which the patient may or may not recognize and the latter refers to the choices made solely by the patient.

${ }^{11}$ The results suggest that these norms are objective and independent of the patient's perspective because this group of respondents rated as less important both the patient's ability to provide needed resources and the patient's own decision preferences. The ability to provide for oneself and the ability to make decisions for oneself comprise central features of one's subjective point of view.
} 
We had a moderate response rate. However, comparing demographic data from non-respondents, wave 1 respondents, and wave 2 respondents suggests that the effect of non-responding on the representatives of our sample was not substantial. Further, we have no reason to believe that the nonrespondents would have had more defined opinions on these issues. Indeed, it seems far more likely that nonrespondents, if anything, would have had fewer well articulated approaches.

It should be also be noted that the researchers provided the list of factors on the survey instrument and this list may have limited respondents' choices and therefore may have exerted some influence on the decision strategies identified. However the 23 items listed were developed by an interdisciplinary team after an exhaustive review of the existing literature. Further, the patterns we described emerged even though the items were presented in a random order on the questionnaire. Finally, the response data revealed no single favored strategy or consensus for medical futility decision-making.

Analyses of the responses did reveal provocative observations regarding the lack of any consensus about the meaning of futility within the hospital setting itself. Our profile analysis suggested that there are at least three independent futility decision policies that professionals endorse. Although the current literature on medical futility tends to focus on physician authority in decision-making, the results indicating a lack of consensus among physician respondents should stimulate more empirical research and caution in allocating futility decisions to the individual physician alone. Nurse respondents differed significantly in their assessment of the importance of certain factors as compared to doctors. Again, this must be tested in further study, but this result has implications for end-of-life care in which nurses play a predominant role, and for the role of multidisciplinary ethics committees in futility decision-making. Results indicating differences among institutions also bear further investigation within the debate concerning the reorganization of health care.

At a minimum, these results indicate a strong likelihood of inconsistency in judgments concerning medical futility in particular cases. Ultimately studies such as the present one will help identify the factors that will form the basis for a consensus concerning these important end of life treatment decisions. This study suggests the manner in which sociolegal research can have an important impact in shaping medical futility policies and law.

\section{ACKNOWLEDGEMENTS}

Partial funding for this project was provided by the Beaumont Faculty Development Fund of Saint Louis University. The research assistance of Lisa L. Portnoff, J.D., a member of the Missouri Bar, is greatly appreciated.

\section{REFERENCES}

Americans with Disabilities Act, 42 U.S.C. $\$ \$ 12101-12213$ (1996).

Asch, D. A., Hansen-Flasche, J., \& Lanken, P. N. (1995). Decisions to limit or continue life-sustaining treatment by critical care physicians in the United States: conflict between physicians' practices and patient's wishes. American Fournal of Respiratory and Critical Care Medicine, 151, 288-292. 
Brennan, T. A. (1992). Physicians and futile care: Using ethics to slow the momentum. fournal of Law, Medicine and Ethics, 20, 336-339.

Child Abuse Prevention and Treatment Act, 42 U.S.C. \$5102, 42 C.F.R. $\$ 1340.15$ (1996).

Christakis, N. A., \& Asch, D. A. (1993). Biases in how physicians choose to withdraw life support. Lancet, 342, 642-646.

Christakis, N. A., \& Asch, D. A. (1995). Physician characteristics associated with decisions to withdraw life support. American fournal of Public Health, 85, 367-372.

Cranford, R., \& Gostin, L. A. (1992). Futility: a concept in search of a definition. Law, Medicine and Health Care, 20, 307-309.

Daar, J. F. (1993). A clash at the bedside: Patient autonomy v. a physician's professional conscience. Hastings Law fournal, 44, 1241-1289.

Fox, E., \& Stucking, C. (1993). Ethics consultants' recommendations for life-prolonging treatment of patients in a persistent vegetative state. Fournal of the American Medical Association, 270, 2578-2582.

Goldner, J. A., Johnson, S. J., \& Wiener, R. L. (1997). Responses to medical futility claims.

In A. G. Gosfield, (Ed.), Health Law Handbook (pp. 401-417). New York: Clark Boardman Callaghan.

Hartsell v. Fort Sanders Regional Medical Center, 905 S.W.2d 944 (Tn. App. 1995).

Health Care Decisions Act, Md. Code Ann., Health-Gen. §§5-601-618 (1994a).

Health Care Decisions Act, Va. Code Ann. \$54.1-2990 (1994b).

In re Baby K, 16 F.3d 590 (4th Cir. 1994).

In re Baby K, 832 F. Supp. 1022 (E.D. Va. 1993).

In re Jane Doe, 18 S.E.2d 3 (Ga. 1992).

In re Wanglie, No. PX-91-283 (Prob. Ct. Hennepin Co., Minn. July 1, 1991).

Johnson, S. H., Gibbons, V. P., Goldner, J. A., Wiener, R. L., \& Eton, D. (1997). Legal and

institutional policy responses to medical futility. Fournal of Health and Hospital Law, 30, 21-36.

Johnson v. Thompson, 971 F.2d 1487 (10th Cir. 1992).

LaSalle National Trust v. Swedish Covenant Hospital. 652 N.E.2d 1089 (Ill. App. 1995).

Lee, D. K. P., Swinburne, A. J., Fedullo, A. J., \& Wahl, G. W. (1994). Withdrawing care: Experience

in a medical intensive care unit. Fournal of The American Medical Association, 271, 1358-1361.

Miles, S. H. (1992). Medical futility. Law, Medicine and Health Care, 20, 310-315.

Morgan v. Olds, 417 N.W. 2d 232 (Ia. Ct. App. 1987).

Morreim, E. H. (1994). Profoundly diminished life: The casualties of coercion. Hastings Center Report, 24, 33-42.

Nightingale, S. D., \& Grant, M. (1988). Risk preference and decision making in critical care situations. Chest, 93, 684-687.

Rehabilitation Act of 1973, 29 U.S.C. §701-797.

Schneiderman, L. J., Faber-Langendoen, K., \& Jecker, N. S. (1994). Beyond futility to an ethic of care. American fournal of Medicine, 96, 110-114.

Solomon, M. Z. (1993). How physicians talk about futility: Making words mean too many things. Fournal of Law, Medicine and Ethics, 21, 231-237.

Solomon, M. Z., O'Donnell, L., \& Jennings, B. (1993). Decisions near the end of life: professional views on life-sustaining treatments. American fournal of Health, 83, 14-23.

SUPPORT (1995). A controlled trial to improve care for seriously ill hospitalized patients: the study to understand prognoses and preferences for outcomes and risks of treatment. Fournal of the American Medical Association, 274, 1591-1599.

Swanson, J. W., \& McCrary, S. V. (1994). Doing all they can: physicians who deny medical futility. Fournal of Law, Medicine E Ethics, 22, 318-326.

Truog, R. D., Brett, A. S., \& Frader, J. (1992). The problem with futility. New England fournal of Medicine, 326, 1560-1564.

Veath, R. M., \& Spicer, C. M. (1992). Medically futile care: the role of the physician in setting limits. American fournal of Law and Medicine, 418, 15-36.

Withholding care from patients: Boston care asks, who decides? (1995, April 3). New York Times, p. 1. 